Environment Conservation Journal 14(1\&2) 21-25, 2013

ISSN 0972-3099 (Print) 2278-5124 (Online)

Abstracted and Indexed

\title{
Repellent activity of essential oils isolated from the leaves of Eupatorium odoratum against malaria, filaria and dengue vectors
}

\author{
M. F. Alam \\ Received:16.12.2012
}

Accepted: 21.03.2013

\begin{abstract}
Light green essential oils extracted from the leaves of Eupatorium odoratum (Asterace) from Himalaya region (India) were screened for repellent activity against Anopheles stephensi, Aedes aegypti and Culex quinquifaciatus mosquitoes. The repellent activity was evaluated in door condition. Four concentrations $2.5 \%, 5 \%, 7.5 \%$ and $10 \%(\mathrm{v} / \mathrm{v})$ in ethanol were considered in this study. When the test oil was applied at $10 \%$ concentration were found most effective and provided more than $2 \mathrm{hr}$ of complete protection against all three mosquito species. The complete protection time (Mean \pm S.D) were recorded as $160.2 \pm 2.77 \mathrm{~min}, 139.4 \pm 1.14 \mathrm{~min}$ and $125.6 \pm 3.13 \mathrm{~min}$ against Anopheles stephensi, Aedes aegypti and Culex quinquifaciatus respectively. There was no bite within $125 \mathrm{~min}$ and $160 \mathrm{~min}$ confirm due to action of essential oil and thus $100 \%$ protection from the bite of mosquitoes achieved. No adverse effects of the human volunteers were observed during the exposure and through three months after the application.Therefore, the essential oil of Eupatorium odoratum (Asterace) may prove useful in the development of mosquito natural repellents as an effective personal protection measure against mosquito bites.
\end{abstract}

Keywords Eupatorium odoratum, Essential oils, Repellency, Mosquito vectors

\section{Introduction}

Mosquitoes are responsible for more diseases than any other group of arthropods, being the major vectors for the transmission of malaria, filariasis, dengue fever, yellow fever, and several viral diseases (Venkatachalam, M. R et. al. 2001). The continuous use of synthetic insecticides creates undesirable effects, toxicity to non target organisms, and human health concerns (Cheng, S. $\mathrm{H}$ et. al. 2003). The use of natural products can be considered an important alternative strategy for the control of mosquito vectors (Carter SW. et. al (1989). Personal protection using repellents is generally accepted as playing a significant role in preventing mosquito-borne diseases by reducing man-mosquito contact. Widely used compound in insect repellents is the synthetic, N, N-diethyl-3Methyl benzamide, also called diethyl toluamide and commonly known as DEET. Although DEET has had a remarkable safety profile for the last 40 years of worldwide use, there are a number of reports on its toxicity against the skin and nervous

\section{Author's Address}

Department of Pharmacology and Toxicology, Faculty of Pharmacy, Jazan University, Jazan, P.O. Box- 114,

Kingdom of Saudi Arabia.

E-mail: firoz.a@rediffmail.com and immune systems, usually occurring when the product is used incorrectly or in the long term (Odalo J.1989).Numerous plants and derived products, in particular essential oils, have been investigated and described as potentially natural sources of insect repellent. Most plant-based insect repellents currently on the market

oils from one or more of the following plants: Citronella (Cymbopogon nardus), Cedar (Juniper virginiana), Eucalyptus (Eucalyptus maculata), Geranium (Pelargonium reniforme), Lemon-grass (Cymbopogon excavatus), Peppermint (Mentha piperita), Neem (Azadirachta indica) and Soybean Neonotonia wightii) (Araujo, E. C. C. et al. 2003, Rajkumar, S. 2004 and 2005). Continuing with our effort to find out the potent natural based alternatives to synthetic repellent, we investigated the essential oil of Eupatorium odoratum (Asterace) for repellent activity against important mosquito vectors. Eupatorium odoratum is a coarse, often straggling shrub bearing exceedingly small, numerous, fragrant flowers. It is an obnoxious weed in the sub Himalayan plains and foothills, covering extensive areas in Assam and Bengal and interfering with the natural regeneration of timber trees in plantations (Gaur, 1999). Recently(Shufen Cuia, et 
al., 2009) Headspace solid-phase microextraction gas chromatography-mass spectrometry analysis of Eupatorium odoratum extract as an oviposition repellent. Ling et al. 2003 found the volatile oil from $E$. odoratum had a significant oviposition deterrent effect on the striped flea beetle (Phyllotreta striolata) and the diamond back moth (DBM) (Plutella xylostella). Some authors work showed that chloroform extract from E. odoratum had oviposition repellent effect against Conopomorpha sinensis. Recently Nurhayat Tabanca et al., 2010 investigated the essential oil of Eupatorium capillifolium (dog-fennel) for antifungal and insecticidal activities. To the best of our knowledge, only some researchers have studied the essential oil of E. odoratum and different type of fraction against different agriculture pest and bacteria but few works has been reported as ovipositional repellent property which stimulates our interest to analyse the activity of this oil for repellent activity. Therefore this study was designed to systematically investigate the repellency of essential oils derived from leaves of Eupatorium odoratum against vector of malaria, filaria and dengue mosquito under laboratory conditions.

\section{Material and Methods \\ Plants}

Leaves of Eupatorium odoratum (Asteraceae), were collected from high altitude mountains (2500m) Garhwal region of North West Himalaya (India) and were identified by the Botanist Dr. Sumer Chand Forest Research Institute Dehradun India.

\section{Extraction}

Leaves (500gm) of Eupatorium odoratum (Asteraceae) were properly washed with distilled water and were subjected to hydro distillation for 4 hrs in a Clevenger-type apparatus to yield $1.40 \mathrm{~g}$ light green essential oils. Then volatile oils dried over anhydrous sodium sulphate after filtration was kept in an amber-colored bottle at $4{ }^{\circ} \mathrm{C}$ until analyzed and tested.

\section{Human volunteers}

Four male volunteers, who had no history of allergic reaction to arthropod bites, were use for repellent activity test. Before start the repellency test the volunteers were interviewed and instructed on the methodology, probable discomforts to subjects and remedial arrangements. The study was reviewed and approved by the Research Ethics Committee of the National Institute of Malaria Research, Haridwar India.

\section{Mosquitoes}

A pathogen-free, mosquito were reared and maintained continuously for several generations in an in-sectary using the standard procedures at National Institute of Malaria Research Hardwar. Prior to testing, female mosquitoes (5-7 days old) were starved by providing them only water for 8 $12 \mathrm{~h}$.

Repellent activity of Essential oils,

Repellent activity of Essential oils which derived from leave of Eupatorium odoratum, were screened for repellency against female blood-starved mosquito under laboratory conditions. The humanbait method Fradin, M.S.et al. (2002) with a slight modification used to determine the repellency, at $27-35{ }^{\circ} \mathrm{C}$ and relative humidity of $70-80 \%$. Essential oil was diluted in ethanol and prepared $2.5 \%, 5 \%, 7.5 \%$ and $10 \%$ concentrations. In each cage one arm was inserted for one test concentration and the other arm applied with ethanol served as control. Before application of the test samples, the arms of volunteers were washed and cleaned thoroughly with distilled water. An aliquot $(0.1 \mathrm{ml})$ of each concentration was applied as uniformly as possible to the skin exposed through a $50 \mathrm{~cm}^{2}$ hole cut in a plastic sleeve that was wrapped around the ventral part of each forearm. After applying the sample, volunteers were instructed to follow the testing protocol. The other forearm, which acted as a control, was treated with absolute EtOH by the same procedure as that for the tested arm. After air drying for $1 \mathrm{~min}$, the treated arm, with gloved hand, was exposed to 50 female mosquitoes in a cage $(40 \times 35 \times 35 \mathrm{~cm})$ for 3 min. The treated and control arms were interchanged regularly to eliminate bias. Each test concentration was repeated five times and in each replicate subject different volunteers to nullify any effect of colour of the skin on repellent.

The mosquitoes that landed on the tested area and attempted to probe and imbibe blood were recorded. Exposure experiments continued at 30 min intervals until at least two bites occurred in a 3min period, or a first bite occurred followed by a confirming bite (second bite) in the next 
observation period. During the experiment, successive introductions of the control arm were performed in the same manner before each insertion of the treated arm, in order to confirm and standardize the readiness of the mosquitoes to bite. The time between application of the plant sample and the first two consecutive bites was considered as the complete-protection time, which was the usual criterion used to determine the repellent efficacy of plant oil. The percentage of repellency was calculated by the following formula.

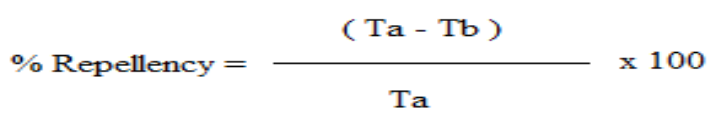

Where $\mathrm{Ta}$ is the number of mosquitoes in the control group and $T_{b}$ is the number of mosquitoes in the treated group.

\section{Stability of essentials oil:}

For the commercial and practical use mosquito repellent needs to maintain its efficacy for an appropriate period of time. The essential oil had been stored at temperature $4^{\circ} \mathrm{C}$ and ambient temperature $25^{\circ} \mathrm{C}$ ) for a 50 days. The essential oils had been retested for repellent activity at 10 days interval to continue 50 days in the laboratory against An.stephensi.

\section{Data analysis}

The obtain data were statistical analysed and standard deviation were calculated in protection time. Differences in significance were determined by comparing the range of protection time of each concentration preparation.

\section{Results and Discussion}

The essential oil was obtained as light green colour from the leaves of Eupatorium odoratum have been studied for use as natural repellents instead of synthetic repellents. The results indicate that the yields of Eupatorium odoratum were 0. 28\% in under shed dried leaves. The repellency of essential oils against An. Stephensi, Aedes aegypti and Culex quinquifaciatus were carried out under laboratory condition is given in Table.1. Results revealed that at $10 \%$ concentration showed complete protection time (Mean \pm S.D) were recorded as $160.2 \pm$ $2.77 \mathrm{~min}, 139.4 \pm 1.14 \mathrm{~min}$ and $125.6 \pm 3.13 \mathrm{~min}$ against Anopheles stephensi, Aedes aegypti and Culex quinquifaciatus respectively while control provided maximum 8.0 minutes protection time
(Fig.1). There was no bite within 120min and 160 min confirm due to action of essential oil and thus $100 \%$ protection from the bite of mosquitoes achieved. In this repellency study, increases in the concentration of the essential oils from $2.5 \%$ to $10 \%$ were found to increase the repellency time. There were significant differences in repellency among the different concentrations of essential oil against An. stephensi. On the other hand, the ethanol applied arm served as control provided maximum 8.0 minutes repellency in this study. No adverse effects of the human volunteers were observed during the study period and through three months after the application. The results obtained in this work indicate that the essential oils which were isolated from Eupatorium odoratum showed promising repellent activity against $A n$. Stephensi in comparison to other vectors. Further the study were continued to find out the stability of essential oils at $4^{\circ} \mathrm{C}$ and ambient temperature $25^{\circ} \mathrm{C}$ ) for a

50days. The results indicated that essential oils $(10 \% \mathrm{v} / \mathrm{v})$ are stable and effective at $4^{\circ} \mathrm{C}$ for $10-30$ days while at the room temperature 10-15days (Fig.2).Many papers on the chemical constituents of essential oils of Eupatorium odoratum have been already published. The yield and chemical constituents, however, show much discordance between the same essential oil. The reasons for this variability due to climatic, seasonal and geographic conditions, harvest period and distillation technique, among others (Panizzi et al.,1993).Chowdhury et al. (2002) studied the essential oils obtained from the leaves of $E$. odoratum collected from Shillong Meghalaya, North-East India and found that the oil contained mainly caryophyllene oxide (18.34\%). Ling et al. (2003) used GC-MS to analyze the volatile oil from E. odoratum and 33 components were identified. Bamba et al. reported that 38 compounds were isolated from E. odoratum oil of which 36 were identified. Lamaty et al. (1992). studied the chemical composition of the essential oils that were obtained from the leaves of E. odoratum collected in Cameroon and Congo. Maria Rose et al.2004 studied the volatile composition of the essential oils from leaves and roots of Eupatorium betonicaeforme (D.C.) A total of 12 compounds were identified. $\beta$-Caryophyllene $(12.4-41.7 \%), \alpha-$ humulene $\quad(11.7-14.6 \%), \quad \gamma$-muurolene $\quad\left(10.4^{-}\right.$ $19.0 \%)$ bicyclogermacrene 
Table.1: Personal protection of essential oils isolated from leaves of Eupatorium odoratum against Anopheles stephensi, Aedes aegypti and Culex quinquifaciatus

\begin{tabular}{|c|c|c|c|c|c|c|}
\hline $\begin{array}{c}\text { Concent } \\
\text { rations } \\
(\% \mathbf{\%} / \mathbf{v})\end{array}$ & \multicolumn{2}{|c|}{$\begin{array}{c}\text { Personal protection in (min) } \\
\text { Anopheles stephensi }\end{array}$} & \multicolumn{2}{c|}{$\begin{array}{c}\text { Personal protection in (min) } \\
\text { Aedes aegypti }\end{array}$} & $\begin{array}{c}\text { Personal protection in (min) } \\
\text { Culex quinquifaciatus }\end{array}$ \\
\cline { 2 - 7 } & $\begin{array}{c}\text { Treated } \\
\pm \text { S.D }\end{array}$ & $\begin{array}{c}\text { Control } \\
\pm \text { S.D* }\end{array}$ & $\begin{array}{c}\text { Treated } \\
\pm \text { S.D }\end{array}$ & $\begin{array}{c}\text { Control } \\
\pm \text { S.D }\end{array}$ & $\begin{array}{c}\text { Treated } \\
\pm \text { S.D }\end{array}$ & $\begin{array}{c}\text { Control } \\
\pm \text { S.D }\end{array}$ \\
\hline 10 & $160.2 \pm 2.77$ & $8.0 \pm 0.71$ & $139.4 \pm 1.14$ & $7.0 \pm 0.71$ & $125.6 \pm 3.13$ & $8.0 \pm 0.71$ \\
\hline 7.5 & $130.6 \pm 3.78$ & $6.8 \pm 0.84$ & $114.2 \pm 3.27$ & $6.8 \pm 0.84$ & $105.6 \pm 3.36$ & $6.8 \pm 0.84$ \\
\hline 5.0 & $109.4 \pm 3.65$ & $5.6 \pm 0.89$ & $96.4 \pm 3.65$ & $5.6 \pm 0.89$ & $89.0 \pm 3.81$ & $5.6 \pm 0.89$ \\
\hline 2.5 & $50.4 \pm 2.70$ & $5.2 \pm 0.84$ & $50.4 \pm 2.70$ & $5.4 \pm 0.44$ & $35.4 \pm 2.30$ & $5.2 \pm 0.84$ \\
\hline
\end{tabular}

* S.D = Standard Deviation, $p<0.05$

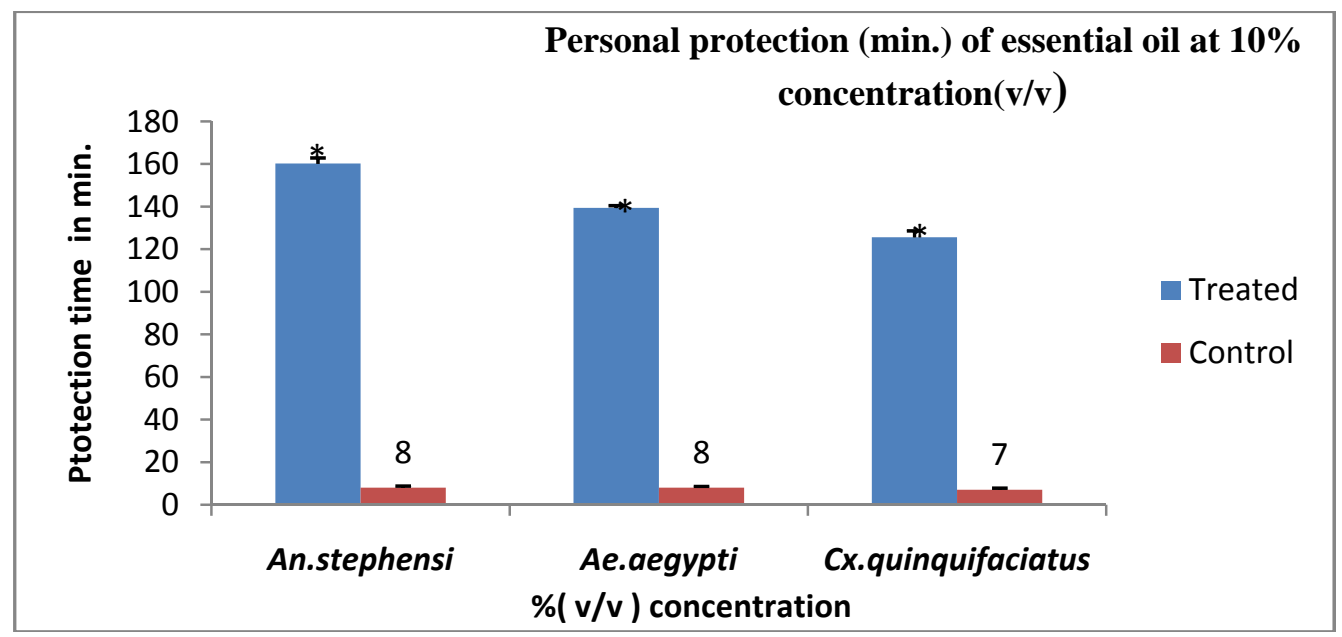

Fig.1: Personal protection (min.) of essential oil isolated from the leaves of Eupatorium odoratum at $h$

Repellent activity of essential oils

s. $(\mathbf{p}<\mathbf{0 . 0 5})$

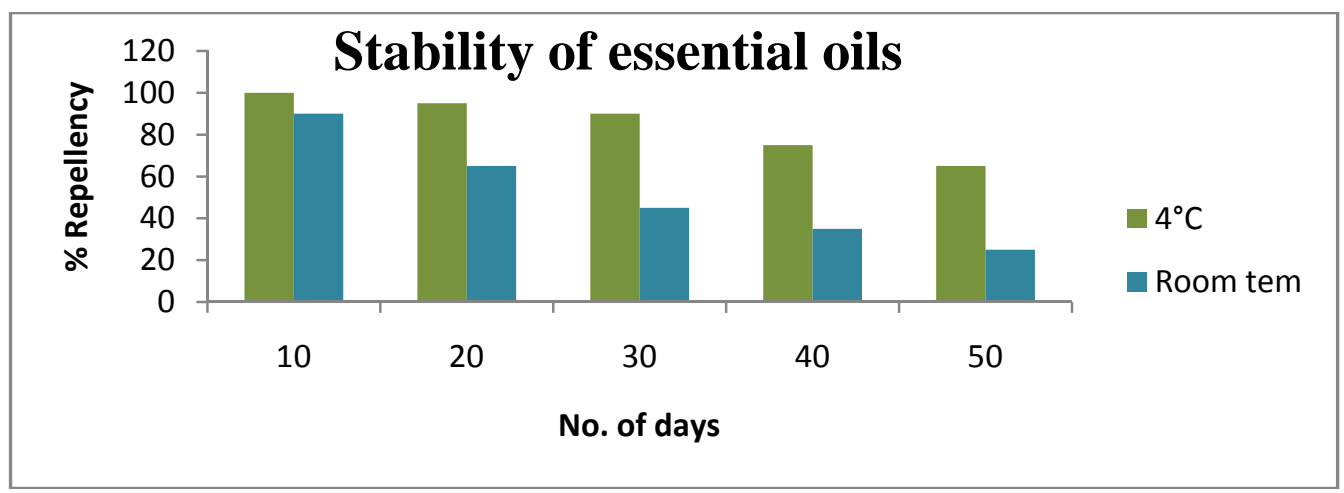

Fig.2: Stability and Repellency of essential oils isolated from the leaves of Eupatorium odoratum against $A n$. stephensi at $10 \%$ concentration (v/v).

investigated the composition of essential oil of

(15.0-17.5\%), 2,2-dimethyl-6-vinylchroman-4-one Eupatorium capillifolium and tested for antifungal $(10.3-25.5 \%)$, and 2-senecioyl-4-vinylphenol and insecticidal activities. The major components $(8.5-41.0 \%)$ were the most prominent constituents. were determined to be thymol methyl ether Recently Nurhayat Tabanca et al., 2010 (=methyl thymol) (36.3\%), 2,5-dimethoxy- 
pcymene $(20.8 \%)$ and myrcene (15.7\%). The E. capillifolium oil showed promising repellent activity against the yellow fever mosquito Aedes aegypti but not other vectors of mosquito. Most of the researcher have studied the essential oil of Eupatorium odoratum composition and their bioactivity against agriculture pest and bacteria but few have study the ovipositonal repellent against mosquito. Most of the research have worked on variety of essential with their repellent activity of different plant species and indicating the protection time less than two hours. In conclusion, the identification of potential repellent plants (Eupatorium odoratum) from the local flora of North West Himalaya Region may promising a novel source of natural repellent, which will generate local employment and stimulate local efforts to enhance public health. Nowadays, the use of plant essential oils in mosquito repellent is an alternative personal protective measure against the noxious effects of synthetic repellents on the users and environment (Thorsell et al., 1998). Therefore,

the essential oil of Eupatorium odoratum (Asteraceae) may prove useful in the development of mosquito repellents as an effective personal protection measure against mosquito bites.

\section{Acknowledgments}

I am thankful to the Dr. V. K. Dua Officer Incharge of National Institute of Malaria Research (ICMR) field station Haridwar, India to provide the lab facilities.

\section{References}

Araujo, E. C. C.; Silveira, E. R.; Lima, M. A. S.; Neto M. A.;de Andrade I. L.; Lima, M. A. A.; Santiago G. M. P.; Mesquita, A. L. M. 2003. Insecticidal activity and chemical composition of volatile oils from Hyptis martiusii Benth. J. Agric. Food Chem. $51,3760-3762$.

Bamba, D., Bessiere, J.M., Marion, C., Pelissier, Y. \& Fouraste, I. 1993 Essential oil of Eupatorium odoratum. Planta Medica, 59, 184-185.

Carter SW. 1989 A review of the use of synthetic pyrethroids in public health and vector pest control. Journal of Pest Science, 27,361-374.

Cheng, S. H.; Chang, H. T.; Chang, S. T.; Tsai, K. H.; Chen, W. J. 2003, Bioactivity of selected plant essential oils against the yellow fever mosquito Aedes aegypti larvae. Bioresource Technol. 89, 99-102.
Chowdhury A.R., 2002 Essential oils of the leaves of Eupatorium odoratum L. from Shillong (N. E.), J. Essen. Oil-Bearing Plants, $5,14-18$

Fradin, M.S. and Day, J.F. 2002. Comparative efficacy of insect repellents against mosquito bites. New England Journal of Medicine 347(1): 13-18.

Gaur, R. D. 1999. Flora of the District Gharwal Northwest Himalaya with ethno botany notes. Book.105; 216; 273; 541-594.

Lamaty, G., C. Menut, P.H. Amvam Zollo, J.R. Kuiate, J.M. Bessière, J.M. Ouamba and T. Silou, 1992. Aromatic plants of tropical Central Africa IV. Essential oils of Eupatorium odoratum (L ). From Cameroun and Congo. J. Ess. Oil Res. 4:101-105.

Ling B, Zhang M, Kong C, Pang X, Liang G 2003 Chemical composition of volatile oil from Chromolaena odorata and its effect on plant, fungi and insect growth. Yingyong Shengtai Xuebao 14, 744-6.

Maria, Rose, Jane, R. Albuquerque, Edilberto R. Silveira, Daniel Esdras, De A. Uchôa, Telma, Leda G. Lemos, Elnatan B. Souza, Gilvandete, Maria P. Nurhayat, Tabanca, Ulrich, R. Bernier, Maia, Tsikolia, James, J. Becnel, Blair, Sampson, Chris, Werle , Betül Demirci , Kemal, Hüsnü Can Başer, Eugene, K. Blythe , Cecil ,Pounders and David, E. Wedge (2010) Natural Product Communications Vol. 5 (9) 1409 - 1415.

Odalo, J, Omolo, M, Malebo, H, Angira J, Njeru, P, Ndiege, I, 2005 Repellency of essential oils of some plants from the Kenyan coast against Anopheles gambiae. Acta Trop; 95: 210-8.

Panizzi, L., Flamini, G., Cioni, P.L. \& Morelli,I. 1993. Composition and antimicrobial Properties of essential oils of 4 Mediterranean Lamiaceae. Journal of Ethnopharmacology 39: 167-170.

Rajkumar, S. and Jebanesan, A. (2004).Mosquitocidal activities of Octacosane from Moschosma polystachyum Linn. (Lamiaceae). Journal of Ethnopharmacolog 90: 87-89.

Rajkumar, S. and Jebanesan, A. 2005. Oviposition deterrent and skin repellent activities of Solanum trilobatum leaf extract against the malarial vector Anopheles stephensi. Journal of Insect Science 5(15):1-3.

Santiago, and Otilia Deusdênia L. Pessoa 2004 Chemical Composition and Larvicidal Activity of the Essential Oils from Eupatorium betonicaeforme (D.C.) Baker (Asteraceae) J. Agric. Food Chem. 52 (22), pp 6708-6711.

Shufen Cuia,Shuo Tanb, Gangfeng Ouyangc,b, Shihong Jianga, Janusz Pawliszynb et al., 2009Headspace solid-phase microextraction gas chromatography-mass spectrometry analysis of Eupatorium odoratum extract as an oviposition repellent Journal of Chromatography B, 877 (2009) 1901-1906,.

Thorsell, W.A., Mikiver, I., Malander \& Tunon, H. 1998. Efficacy of plant extracts and oils as mosquito repellents. Phytomedicine 5: 311-323.

Venkatachalam, M. R., Jebanesan, A. 2001Repellent activity of Ferronia alephantum Corr. (Rutace ae) leaf extract against Aedes aegypti (L). Bioresource Technol., 76, 287-288. 